\title{
INTEGRAÇÃO DE AULAS PRÁTICAS E TEÓRICAS DA DISCIPLINA DE GEOMETRIA DESCRITIVA NA MODALIDADE EAD
}

\author{
LONDRINA/PR JUNHO/2018
Debora Cristiane Barbosa Kirnev - UNOPAR - deborabarbosa09@yahoo.com.br Flávio Augusto Carraro - UNOPAR - flavio.carraro@hotmail.com \\ Tipo: Relato de Experiência Inovadora (EI) \\ Categoria: Métodos e Tecnologias \\ Setor Educacional: EDUCAÇÃO SUPERIOR

\begin{abstract}
RESUMO
Neste trabalho desenvolvemos um relato de experiência sobre o planejamento e execução da disciplina de Geometria Descritiva aplicada a Arquitetura de um curso de Arquitetura e Urbanismo na modalidade EAD, em que utilizamos os recursos tecnológicos disponíveis para favorecer a aprendizagem dos estudantes na execução de aulas práticas e teóricas promovendo a mediação desse processo por meio de mídias.
\end{abstract}

Palavras-chave: Ensino EaD. Ensino de Geometria Descritiva. Mediação no ensino EaD.

\section{AGRADECIMENTOS}

AGRADECEMOS A NOSSA INSTITUIÇÃO, AOS FAMILIARES E AMIGOS PELO APOIO. 


\section{Introdução}

A Geometria Descritiva é uma disciplina de base para a formação discente em um curso de Arquitetura e Urbanismo. Nesta disciplina trabalha-se a compreensão e formação do pensamento geométrico, conhecimento das formas planas e espaciais e as características destas. Objetiva-se criar um repertório por meio de um vocabulário formal, para que aplicado, por exemplo, em um projeto de arquitetura, contribuía para interação e percepção deste com os usuários o meio em que se está inserido.

Neste sentido, as atividades realizadas possibilitam desenvolver habilidades práticas de desenho, além de técnicas e métodos relacionados à geometria das formas, dando-lhe maior compreensão dos meios de expressão e de representação gráfica que viabiliza a criação de soluções em projetos arquitetônicos.

Neste trabalho relatamos sobre o desenvolvimento da disciplina de Geometria Descritiva Aplicada à Arquitetura ministrada em um curso de Arquitetura e Urbanismo - EaD com alunos regularmente matriculados e desenvolvida, considerando pelo menos dois momentos, o primeiro teórico desenvolvido em teleaulas ao vivo e complementado por atividade direcionada a cada aula, o segundo pelo desenvolvimento de aula prática, executadas em sala de desenho, provisionado na infraestrutura do polo.

\section{Referencial teórico}

Diante das tendências atuais de ensino, a modalidade EaD destaca-se apresentando um grande crescimento nas últimas décadas. De acordo com legislação da Educação a Distância, o artigo $1^{\circ}$ do Decreto ํㅜ․ 622/2005 caracteriza como:

modalidade educacional na qual a mediação didático pedagógica nos processos de ensino e aprendizagem ocorre com a utilização de meios e tecnologias de informação e comunicação, com estudantes e professores desenvolvendo atividades educativas em lugares ou tempos diversos. (DECRETO $n^{\circ}$ 5.622, DOU 20/12/2005)

Salientamos que na segunda metade do século XX surgiram as primeiras instituições no Brasil na modalidade à distância, mais essa forma de ensino já ocorria no exterior. Neste período alguns pesquisadores dessa modalidade de ensino já investigavam sobre as metodologias e os elementos envolvidos no processo de ensino e aprendizagem. Dentre eles, destacamos os resultados Desmond Keegan que aponta alguns elementos chave no processo de ensino nesta modalidade, tais como:

- distância física entre professores e alunos;

- influência de uma organização educacional; 
- uso da mídia para interligar professores e alunos;

- troca de comunicação bidirecional;

- aprendizes vistos como indivíduos, ao invés de grupos de alunos. (KEEGAN, 1996 apud MUGNOL, 2009, p. 338)

Segundo Moran (online, p. 1) atualmente "ensinar e aprender exigem hoje muito mais flexibilidade espaço temporal, pessoal e de grupo, menos conteúdos fixos e processos mais abertos de pesquisa e de comunicação." O autor apresenta como os meios de comunicação podem mediar o processo de ensino e aponta que:

\footnotetext{
Os Meios de Comunicação operam imediatamente com o sensível, o concreto, principalmente, a imagem em movimento. Combinam a dimensão espacial com a cinestésica, onde o ritmo torna-se cada vez mais alucinante (como nos videoclips). Ao mesmo tempo utilizam a linguagem conceitual, falada e escrita, mais formalizada e racional. Imagem, palavra e música se integram dentro de um contexto comunicacional afetivo, de forte impacto emocional, que facilita e predispõe a aceitar mais facilmente as mensagens. (MORAN, online, p. 4)
}

No caso do ensino EaD da disciplina de Geometria Descritiva em um curso de Arquitetura e Urbanismo, temos como finalidade contribuir para formação do profissional visando o desempenho de "habilidades de desenho e o domínio da geometria, de suas aplicações e de outros meios de expressão e representação, tais como perspectiva, modelagem, maquetes, modelos e imagens virtuais". (MEC, resolução 02/ 2017, p.3, online).

Com o desenvolvimento tecnológico, ferramentas derivadas da computação surgem e com isso precisamos repensar no ensino da Geometria Descritiva aliada com os recursos disponíveis. Temos que o objetivo desta disciplina é "desenvolver, no aluno, a habilidade de representar em duas dimensões, objetos tridimensionais idealizados ainda na mente de criados [visualização espacial do objeto]" (TORRES, VIEIRA, MARTINS FILHO, p.313).

No andamento da disciplina de Geometria Descritiva aplicada a Arquitetura e Urbanismo, foco deste relato, tivemos como grande desafio promover a integração de aulas teóricas e práticas e julgamos pertinente realizar apontamentos sobre este desenvolvimento, para tanto apresentamos como foi o planejamento e execução dela.

\section{Contexto do desenvolvimento da disciplina}

A referida disciplina foi ofertada no segundo semestre de 2017 , e seu posicionamento dentro da estrutura do curso está relacionada ao segundo semestre da primeira série dentro curso de Arquitetura e Urbanismo. 
O modelo pedagógico adotado para a modalidade à distância é bimodal e multimidiático. Bimodal justifica-se pela composição do sistema em atividades presenciais e a distância, síncronas e assíncronas, como também pela utilização de diferentes mídias na transmissão e construção do conhecimento. Quanto em relação a qualidade multimidiática ocorre pela utilização de um conjunto de mídias e linguagens em que o curso de arquitetura disponibiliza ao aluno, seguindo o modelo pedagógico da modalidade: aulas via satélite ao vivo, web aula, portfólio eletrônico, bibliotecas digital e virtual, objetos digitais, vídeo e material didático impresso e eletrônico.

Ressaltamos que o aluno possui o papel fundamental no seu processo de ensino e aprendizagem. Na vigência da disciplina, o discente, além de poder realizar a interação com o professor em aulas ao vivo e aula atividade, em aulas práticas, com o apoio do tutor presencial e com formação específica, também tem um conjunto de instrumentos de apoio à aprendizagem que pode desenvolver pelo ambiente virtual de aprendizagem (AVA), e contar com o apoio de um tutor à distância, com formação específica em arquitetura, nos momentos que estiver desenvolvendo o auto estudo, comunicação que ocorre por meio de sistema de mensagem e um ambiente virtual denominado sala do tutor.

Com relação aos materiais disponibilizados no AVA, destacamos que adotamos como base o livro texto subdividido em quatro unidades temáticas, associado uma webaula para cada capítulo, esta compostas por hipertextos que sintetizam tema de conteúdo explorando o uso de link, imagens e vídeos que complementam o material.

A partir da ementa prevista no Projeto Pedagógico do Curso (PPC), e por meio dos materiais disponibilizados no AVA, adota-se subdivisão dos conteúdos, conforme direcionamento teórico e prático possíveis, sendo quatro teleaulas e quatro aulas práticas.

O modelo pedagógico do curso é baseado em três momentos de aprendizagem. Uma aula é subdividida em três momentos de estudos que são a pré-aula, aula e pós-aula.

- A pré-aula, objetiva que o aluno acesse materiais da disciplina disponibilizados no AVA (webaulas, livro didático, fóruns de discussão), a partir disso, desenvolva atividades e leituras que são o aporte teórico da disciplina.

- No momento da aula é proposto uma situação geradora de aprendizagem (SGA) que refere-se à um contexto geral a ser trabalho na aula baseado no aporte teórico. A SGA é acompanhada de situações problemas, propostas pelo docente, visando a correlação da teoria sendo aplicada em uma situação da realidade 
profissional.

- No momento de pós-aula são realizadas atividades relacionadas com a aula, elaboradas pelo docente, que visam aprofundar o conteúdo abordado.

Está metodologia á aplicada tanto para teleaulas teóricas como para as aulas práticas.

Para a realização das teleaulas, com a exploração do aporte teórico, há semanalmente o encontro presencial no polo que os estudantes assistem a transmissão ao vivo de uma hora e trinta minutos. De modo assíncrono, ocorre previamente por meio do fórum, a indicação de estudos teóricos anteriores a teleaula que caracteriza o estudo da pré-aula. Complementando há aula atividade, como um momento de pós-aula, proposta pelo professor, na qual ocorre com duração de uma hora sob supervisão do tutor presencial, onde os alunos aplicam os conhecimentos obtidos em atividades referentes aos conteúdos.

Salientamos que existe mais de um momento de interação com o aluno e tutor presencial, com o professor e tutor a distância, primeiramente ao vivo, pelo chats de interação da teleaula e aula atividade no momento da transmissão, e depois por sistema de mensagens em que o aluno, consegue dirimir suas dúvidas de forma individualizada.

Além da teleaula, semanalmente são agendadas uma aula prática, tendo por base a carga horária prevista no PPC, divididas em três momentos a pré-aula na qual o estudante assiste uma aula gravada disponibilizada em seu AVA, a realização da aula juntamente com um tutor presencial no polo na qual está regularmente matriculado e a pós - aula que consiste na finalização das atividades propostas na aula prática.

Para a preparação das aulas práticas, o docente adota como referencia livro texto. Para cada capítulo temos um conjunto de roteiros de aulas práticas, do qual o professor pode sugerir práticas de desenho, desenvolvido em laboratório com prancheta de desenho e régua paralela, e demais instrumentos de desenho, como por exemplo, esquadros (30, 45 e 60 graus) compasso, lapiseira entre outros nos quais já constam na lista de materiais que o aluno deve possuir para praticar a disciplina.

No andamento da disciplina, de forma coletiva e de modo assíncrono, os fóruns de discussões visam contribuir para o processo de ensino aprendizagem, sob a supervisão dos tutores a distância e o professor da disciplina instigando o aluno diante de questionamentos propostos ao longo da disciplina. Destacamos que, tanto as teleaulas como as aulas práticas têm um fórum de discussão semanal, que o professor propõe, sugerindo ao aluno posicionamentos em relação aos conteúdos ministrados, e tais 
questionamentos são lançados pelo docente de modo que haja construção coletiva e contributiva sobre uma determinada temática trabalhada dentro da disciplina.

\section{Integração das aulas práticas e teóricas}

Conforme exposto anteriormente, a preparação das aulas práticas é baseada no aporte teórico do livro texto e dos roteiros disponíveis em cada unidade, que contém atividades que são propostas ou adaptadas na execução destas aulas. Levando em consideração a carga horária de prática prevista no PPC e um cronograma previamente estabelecido pela coordenação, o professor desenvolve vídeo aulas, que são disponibilizados no AVA.

O aluno por sua vez é orientado a assistir antes da participação da aula prática no polo, de modo assíncrono, a videoaula de prática como momento de pré-aula. Posteriormente na data agendada para aula prática, com o apoio do polo e tutor presencial, o aluno se direcionará ao laboratório de desenho para execução da aula composta por uma sequência de atividades pré-estabelecidas pelo professor.

Para a realização da aula prática, ocorre o agendamento via sistema de monitoramento remoto e há supervisão em tempo real por auditores que possuem formação específica em arquitetura. Isto ocorre devido ao fato de ser exigido do polo um conjunto de câmeras dentro dos laboratórios que possibilita supervisionar as aulas remotamente.

$\mathrm{Na}$ execução da aula prática os alunos são orientados pelo tutor presencial, que recebe, com sete dias de antecedência, um vídeo específico com instruções das atividades e também as aulas disponibilizadas no AVA para os discentes. Este fornecimento de instruções tem como finalidade que tutor presencial provisione e prepare os laboratórios para a aula prática e tenha tempo hábil de elucidar suas próprias dúvidas com 0 professor da disciplina ou com o tutor a distância.

O monitoramento remoto visa garantir que o polo execute as aulas dentro do cronograma desenvolvido pela coordenação, e também que o professor possa monitorar e verificar junto ao auditor educacional se as práticas estão transcorrendo de acordo como o planejado. O apoio educacional assim de modo síncrono é feito pelo tutor presencial e polo, e o assíncrono pelo professor e tutor a distância todos engajados em trabalhar as habilidades e competências que o projeto pedagógico do curso prevê no processo de ensino aprendizagem direcionado a disciplina em questão.

Apresentamos um quadro síntese das aulas práticas desenvolvidas nesta disciplina: 
QUADRO 1 : síntese do desenvolvimento das aulas práticas

\begin{tabular}{|c|c|c|}
\hline Aula prática & Descrição & $\begin{array}{l}\text { Competências e } \\
\text { habilidades }\end{array}$ \\
\hline 1 & $\begin{array}{lrr}\text { Foram } & \text { propostas } & \text { três } \\
\text { situações } & & \text { problemas } \\
\text { envolvendo } & \text { respectivamente: } \\
\text { sistemas de } & \text { coordenadas; } \\
\text { sistemas } & \text { de } & \text { projeções } \\
\text { ortogonais; } & \text { vistas } \\
\text { isométricas. } & \end{array}$ & $\begin{array}{l}\text { - Conhecer o sistema } \\
\text { de projeção } \\
\text { ortogonal. } \\
\text { - Desenvolver } \\
\text { projeções de objetos } \\
\text { planos e espaciais. }\end{array}$ \\
\hline 2 & 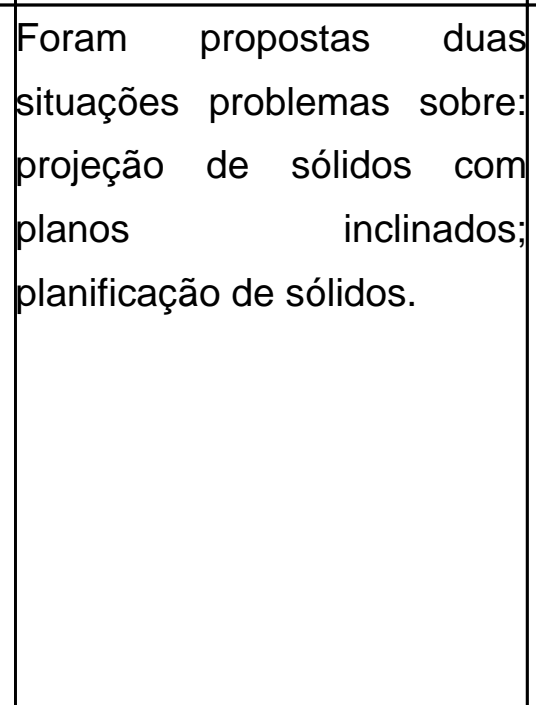 & $\begin{array}{l}\text { - Reconhecer as } \\
\text { diferentes formas } \\
\text { geométricas; } \\
\text { - Analisar as diferentes } \\
\text { projeções: planos } \\
\text { paralelos, planos } \\
\text { ortogonais, planos } \\
\text { inclinados. } \\
\text { - Representar formas } \\
\text { espaciais de modo } \\
\text { planificado. }\end{array}$ \\
\hline 3 & $\begin{array}{|lrr|}\text { Foram } & \text { propostas } & \text { duas } \\
\text { situações } & \text { problemas: } \\
\text { primeira } & \text { sobre } & \text { a } \\
\text { representação } & \text { das } & \text { vistas } \\
\text { isométricas. } & \text { A } & \text { segunda } \\
\text { sobre a } & \text { aplicação de } & \text { cortes } \\
\text { em peças simples. }\end{array}$ & $\begin{array}{l}\text { - Identificar as } \\
\text { representações em } \\
\text { épura no primeiro } \\
\text { diedro; } \\
\text { - Representar nos } \\
\text { eixos ortogonais } \\
\text { formas espaciais } \\
\text { simples na } \\
\text { perspectiva } \\
\text { isométrica. } \\
\text { - Identificar os } \\
\text { diferentes tipos de } \\
\text { cortes aplicados a } \\
\text { peças simples. }\end{array}$ \\
\hline 4 & $\begin{array}{l}\text { Foi proposta uma situação } \\
\text { problema que foi subdividida }\end{array}$ & $\begin{array}{l}\text { - Associar as } \\
\text { representações em }\end{array}$ \\
\hline
\end{tabular}




\begin{tabular}{|lrr|l} 
em duas formas & de & épura com as \\
representação na & qual & elevações e cortes \\
aplicamos cortes em & uma & aplicadas a projetos \\
edificação simples. & & arquitetônicos. \\
\hline
\end{tabular}

Fonte: dos autores (2018).

Destacamos a seguir alguns comentários relatados no fórum da disciplina:

COMENTÁRIO 1: ( sobre o estudo da teleaula 1 e aula prática 1) - "Vamos para mais uma aula hoje! Adorando essa matéria!" (GOMES, F. C. A. L. - 1ํsemestre, 2017, online)

Neste comentário evidenciamos o entusiasmo do estudante no momento na primeira semana de vigência da disciplina.

COMENTÁRIO 2: ( sobre o estudo da teleaula 2 e aula prática 2) "Adorei fazer os exercícios das aulas práticas... Bem interessante o método!" (GOMES, F. C. A. L. - 1ํsemestre, 2017, online)

Neste comentário o estudante nos apresenta um feedback positivo sobre a metodologia empregada no desenvolvimento das aulas práticas.

COMENTÁRIO 3: (sobre o estudo da teleaula 3 e aula prática 3) - "Obrigada por nos auxiliar uma sequencia de exercícios onde pude sanar dúvidas, tanto nas projeções ortogonais, rebaixos e oblíquos, quanto nas vistas isométricas." (BORGES, D. A. $-2^{\circ}$ semestre, 2017, online)

Neste fórum adicionamos micro aulas disponibilizadas e canal do Youtube para complementar o material disponibilizado para a disciplina e recebemos um retorno favorável sobre essa prática.

COMENTÁRIO 4: ( Sobre o estudo da teleaula 4 e aula prática 4) "Muito bom estudar essas normas como saber aplicá-las , elas tiram muitas dúvidas.” (CONEGUNDES, C. P - 2ํsemestre, 2017, online)

COMENTÁRIO 5: ( Sobre o estudo da teleaula 4 e aula prática 4) "Estas normas contribuem de forma construtiva, pois nos auxiliam bastante no entendimento e concepção do conteúdo. Muito obrigado !!"( CARMO NETO, J. R. $2^{\circ}$ semestre, 2017, online)

Neste fórum da teleaula 4 adicionamos materiais complementares: NBR 8403 aplicação de linhas em desenho técnico; NBR 10067 - Princípios gerais de representação em desenho técnico; NBR 12298 - Representação de área de corte por meio de hachuras em desenho técnico. Essa disponibilização também promoveu um bom retorno por parte dos estudantes. 


\section{Considerações}

Perante do desafio de promover a aprendizagem de habilidades práticas de desenho na modalidade EaD, entendemos que o principal papel do professor é mediar a aprendizagem, gerenciando todos os recursos disponíveis, sejam recursos humanos como tutores a distância e tutores presenciais, ou ainda recursos tecnológicos como as interações em instrumentos de interação eletrônica, fórum, chats, sistemas de mensagens e sala do tutor.

Para atingir este propósito, os materiais disponibilizados no AVA, e os materiais preparados pelo professor (slides de tela aulas, aulas atividades, slides de aulas práticas, fórum), visam criar o comportamento de auto estudo, e aplicar os conhecimentos de geometria, a fim de ter condições de representar graficamente os entes geométricos abordados.

Neste sentido, temos o aluno sendo o principal ator de seu desenvolvimento, norteado pela proposição de desafios baseados na realidade profissional e que pela problematizações colocadas pelo professor. A devolutiva dos alunos ocorre por meio de todos os instrumentos de interação eletrônica, chats de tele aulas e aula atividade (síncrono), fóruns (assíncrono), sistemas de mensagens (assíncrono) e sala do tutor à distância (assíncrono), que servem de termômetro, de como os alunos estão conseguindo assimilar os conteúdos.

Diante do exposto, entendemos que o bom aproveitamento do aluno dos diferentes recursos didáticos e a exploração de mídias e materiais que integraram diversos momentos do andamento da disciplina, possibilita o desenvolvimento de competências e habilidades essenciais para a formação do pensamento geométrico, tão essencial para as práticas profissionais do futuro arquiteto.

\section{Referências}

BRASIL. Decreto no 5.622 - Diretrizes e bases da Educação Nacional, de 19 de dezembro de 2005. Art. 80 da Lei no 9.394 de 20 de dezembro de 1996. Publicado no Diário Oficial da União de 20/12/2005. Disponível em < http://www2.camara.leg.br/legin/fed/decret/2005/decreto-5622-19-dezembro-2005-53965 4-norma-pe.html > Acesso em 19/04/2018. 
BRASIL. MEC - Resolução no 2 , de 17 de junho de 2010. Disponível em < http://portal.mec.gov.br/index.php?option=com_docman \&view=download \&alias=5651-rc es002-10\&ltemid=30192> Acesso 19/04/2018.

MORAN, J. M.. O Uso das Novas Tecnologias da Informação e da Comunicação na $E A D$ - uma leitura crítica dos meios. Disponível em $<$ http://portal.mec.gov.br/seed/arquivos/pdf/T6\%20TextoMoran.pdf> Acesso em 19/04/2018.

MUGNOL, M.. A EDUCAÇÃO A DISTÂNCIA NO BRASIL: conceitos e fundamentos. ISSN 1518-3483. Rev. Diálogo Educ., Curitiba, v. 9, n. 27, p. 335-349, maio/ago. 2009.

TORRES, E. A. B.; VIEIRA, C. L. B.; MARTINS FILHO, P. B.. A importância da geometria descritiva no ensino da engenharia. Disponível em < http://www.abenge.org.br/cobenge/arquivos/20/st/s/s076.PDF> Acesso em 19/04/2018. 